\title{
Effect of climate change on the energy performance and thermal comfort of high-rise residential buildings in cold climates
}

\author{
Fuad Mutasim Baba ${ }^{1, *}$, and Hua Ge \\ ${ }^{1}$ Concordia University, Department of Building, Civil and Environmental Engineering, Montreal, \\ Canada
}

\begin{abstract}
Buildings now produce more than a third of global greenhouse gases, making them more than any other sector contributing to climate change. This paper investigates the effect of climate change on the energy performance and thermal comfort of a high-rise residential building with different energy characteristic levels, i.e. bylaw to meet current National Energy Code of Canada for Buildings (NECB), and passive house (PH) under two climate zones in British Columbia, Canada. SRES A2, RCP-4.5 and RCP-8.5 emission scenarios are used to generate future horizon weather data for 2020,2050, and 2080. The simulation results show that for both bylaw and PH cases, the heating energy consumption would be reduced while cooling energy consumption would be increased. As a result, for the bylaw case, the total energy consumption would be decreased for two climate zones, while for PH case, the total energy consumption would be increased for zone 4 and decreased for zone 7 . In addition, the number of hours with overheating risks would be increased under future climates, e.g. doubled in 2080, compared to the historical weather data. Therefore, efforts should be made in building design to take into account the impact of climate change to ensure buildings built today would perform as intended under changing climate.
\end{abstract}

Keywords: effect of climate change, whole building energy modelling, overheating risk

\section{Introduction}

The greenhouse gases (GHG) are one of the main causes for climate change [1]. The building sector produces $23 \%$ of greenhouse emissions in Canada [2]. Therefore, Canada, specifically British Columbia (BC), set the target to reduce the GHG from building sector by building all new buildings with net-zero energy consumption by 2032 . However, the common practice of assessing the energy performance of buildings is to use historical weather data (Typical Meteorological Year TMY), while NASA data showed that there are significant changes in the current climate compared to the historical weather [3]. Therefore, the energy consumption of energy efficient or net-zero energy buildings may be

* Corresponding author: fu_baba@live.concordia.ca 
significantly affected by these undesirable changes. Intergovernmental Panel on Climate Change (IPCC) has been established since 1988 to investigate the causes and impact of climate change and measures to mitigate the effects of climate change.

In recent years, research has been carried out on the impact of climate change on energy performance of buildings based on Third or Fourth IPCC scenarios [4-8]. For instance, Shen concluded that the total energy use of residential and office buildings in USA would increase by $14 \%$ and $3 \%$, respectively in 2050 in warm climate zones [7]. In Canada, Robert et al. [8] found that the net-zero energy buildings would not be able to maintain the net-zero status by 2050 as a result of climate change. However, climate change will not only affect the energy performance of buildings, but also the thermal comfort of occupants. UK has released studies on overheating in buildings under future climate and how to mitigate the climate change effect on indoor thermal comfort. A number of European studies showed that under the current climate the overheating risks have been increased to $44 \%$ in bedrooms and $29 \%$ in living rooms compared to the historical weather [9-11]. However, there are very limited studies on this subject in Canada. This paper aims to assess the energy performance and thermal comfort of a high-rise residential building in British Columbia that is built based on the current and future energy codes under historical and future climatic conditions.

\section{Methodology}

\subsection{Case study building}

To study the climate change effect on the energy performance of residential buildings, a high-rise multi-unit residential building is selected. Figure 1 shows the sketch up of the high-rise residential building. The archetype building is the same building that used in the BC Hydro Power Smart guide [12] to represent a typical multi-unit high-rise residential building built in recent years in BC. The selected building has 30 -storey with a window wall ratio of $40 \%$. The gross floor area of the building is $27,871 \mathrm{~m}^{2}$ and its length to width ratio is $1: 1$ and wall to roof ratio is 10.8 , respectively.

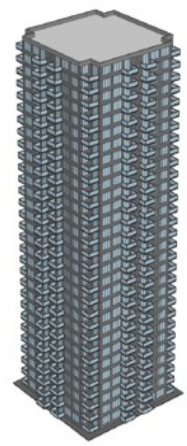

Fig. 1. Sketch up of the high-rise building. Dimension in $\mathrm{m}$. [12]

\subsection{Building envelope components}

The high-rise building chosen is a pour-in-place concrete construction with exterior insulation. The configurations of the building envelope assemblies that adopted from BC Hydro Power Smart report [12] are used as bylaw case and varying insulation thickness are 
used for PH cases. The overall thermal transmittance of building envelope assemblies are listed in Table 1 for bylaw and PH case. Bylaw design refers to building envelope assembly meets the current NECB building code requirement for the specific climate zone, while PH design refers to building envelope assembly to meet the energy performance of $\mathrm{PH}$ standard requirement.

Table 1. Overall thermal transmittance of building envelope assemblies

\begin{tabular}{l|l|l|l|l} 
& \multicolumn{2}{|l}{$U\left(\mathrm{~W} / \mathrm{m}^{2} . K\right)$} \\
Zone 4 (Vancouver) & \multicolumn{2}{l}{$\begin{array}{l}\text { Zone } \\
\text { Nelson) }\end{array}$} \\
\cline { 2 - 5 } & Bylaw & PH & Bylaw & PH \\
\hline $\begin{array}{l}\text { Exterior above } \\
\text { grade wall }\end{array}$ & 0.28 & 0.20 & 0.20 & 0.07 \\
\hline Roof & 0.21 & 0.18 & 0.15 & 0.09 \\
\hline Ground floor & 0.23 & 0.18 & 0.23 & 0.15 \\
\hline Window & 1.50 & 0.78 & 1.50 & 0.60 \\
\hline
\end{tabular}

\subsection{Generation of future weather data}

The building is simulated under the historical (TMY) and predicted future horizon data of 2020, 2050, and 2080 for two climatic zones, i.e. Vancouver (zone 4) and Fort Nelson (zone 7), using DesignBuilder. The SRES A2, RCP 4.5 and RCP 8.5 emission scenarios are used to generate future climate. CCWorldWeatherGen tool, which uses the morphing method for temporal and spatial downscaling, is used to generate future horizon years based on HadCM3 General Circulation Models (GCM) for A2 scenario. While, WeatherShift tool, which also uses the morphing method for temporal and spatial downscaling, is used to generate future horizon years based on $14 \mathrm{GCM}$ for RCP 4.5 and 8.5 generation.

\subsection{Thermal comfort criteria}

The overheating risks are evaluated based on the operative temperature ranges for naturally conditioned spaces according to ASHRAE 55-2017 [13]. Equation 1 determines the upper limit temperature that corresponds to the acceptable operative temperature. If the operative temperature (equation 2) is higher than upper limit temperature, overheating will occur.

$$
\begin{gathered}
\text { Upper } 80 \% \text { acceptable limit } \mathrm{T}_{\mathrm{c} \text {,up }}=21.3+0.31 * \mathrm{~T}_{\mathrm{om}} \\
\qquad \mathrm{T}_{\mathrm{o}}=\left(\mathrm{T}_{\mathrm{d}}+\mathrm{T}_{\mathrm{mrt}}\right) / 2
\end{gathered}
$$

Where $\mathrm{T}_{\mathrm{om}}$ is the monthly mean outdoor air dry-bulb temperature $\left({ }^{\circ} \mathrm{C}\right), \mathrm{T}_{\mathrm{o}}$ is the operative temperature $\left({ }^{\circ} \mathrm{C}\right), \mathrm{T}_{\mathrm{d}}$ is the indoor air dry-bulb temperature $\left({ }^{\circ} \mathrm{C}\right)$, and $\mathrm{T}_{\text {mrt }}$ is the mean radiant temperature of the zone $\left({ }^{\circ} \mathrm{C}\right)$.

The overheating risk is analysed for the base-case that represents the bylaw building without natural ventilation, mechanical cooling or mechanical ventilation; and it is simulated under historical year (TMY data). In addition to the base-case, seven cases are simulated to evaluate the effect of climate change on the thermal comfort. These seven cases are: 1) base-case under 2080 weather; 2) PH case under historical weather; 3) PH case under 2080 weather; 4) base-case with natural ventilation under historical weather; 5) basecase with natural ventilation under 2080 weather ; 6) PH case with natural ventilation under historical weather; and 7) PH case with natural ventilation under 2080 weather. 


\subsection{Settings in whole building energy simulations}

The settings of whole building energy simulation are based on NEBC-2017 [14]. The heating and cooling set point are $22{ }^{\circ} \mathrm{C}$ and $24{ }^{\circ} \mathrm{C}$, respectively, and the heating set-back is $18{ }^{\circ} \mathrm{C}$. The COP of the heat pump is 1.7 in winter and 3.5 in summer. The light and appliances and plug loads are 5 and $5.5 \mathrm{~W} / \mathrm{m}^{2}$, respectively. Mechanical ventilation is with $65 \%$ and $90 \%$ heat recovery efficiency for bylaw and $\mathrm{PH}$ cases, respectively. For overheating simulation with natural ventilation (free cooling simulation), the natural ventilation is activated (by opening $20 \%$ of the windows area), if the indoor temperature is higher $24^{\circ} \mathrm{C}$ and higher than outdoor temperature. The amount of natural ventilation is calculated based on wind speed, wind pressure, wind direction and the size of window opening.

\section{Results and discussions}

\subsection{Annual heating, cooling and total energy consumption}

As shown in Table 2, the annual heating energy demand of bylaw building in 2080 would be reduced by $27-43 \%$ compared with under historical weather data in Vancouver. However, the cooling energy demand would be increased by up to $3800 \%$ and account for about $50 \%$ of the total energy demand compared to $1 \%$ under historical weather. Similar results were obtained for Fort Nelson city, where the annual heating energy demand would be reduced by $14-23 \%$, while the cooling energy demand portion would be increased from $3 \%$ to $22 \%$ of the total energy demand. Energy efficient buildings would be affected by climate change more than bylaw buildings. The cooling energy demand of these buildings would be higher than the heating energy demand in 2080 under moderate climate (Vancouver City) and failed to meet PH requirements for the cooling energy demand. Under very cold climate (Fort Nelson City), the cooling energy demand portion in 2080 would be almost equal to the heating energy demand, but could still meet the PH requirements.

Figure 2 shows the total annual energy consumption of the building, which includes the heating and cooling energy consumption of HVAC system and the light and appliances load, and the percentage difference in annual energy consumption between historical year and 2080 . The total energy consumption would be reduced by $5-30 \%$ for all cases except for the $\mathrm{PH}$ case in Vancouver, where the total energy consumption would be increased by $16 \%$ in 2080 . The increase in total energy consumption for Vancouver is primarily due to the increase of cooling energy demand and the decrease of the efficiency of heat pump system, where the COP would be 3.0 in summer of 2080 due to the higher ambient air temperature. 
a)

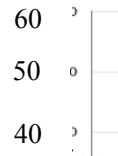

Annual energy co

$(\mathrm{KWh} / \mathrm{m}$

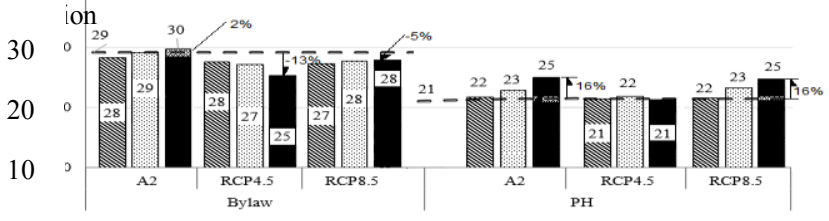

$2020 \quad 2050$ - 2080 - Typical year

b)

60

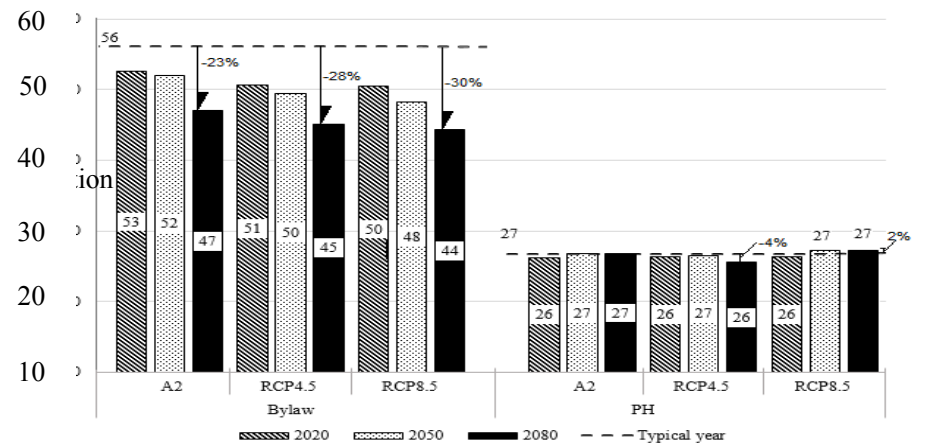

Annual energy cc

(KWh/n

Fig. 2. Annual energy consumption under a) Vancouver; b) Fort Nelson for bylaw and PH cases and change in annual energy consumption by \% (from historical to 2080)

Table 2. Comparison of annual heating and cooling energy demand $\left(\mathrm{KWh} / \mathrm{m}^{2}\right)$ between historical and 2080 climate data

\begin{tabular}{l|ll|ll|ll|ll|} 
& \multicolumn{3}{|l}{ Vancouver } & \multicolumn{9}{l|}{ Fort Nelson } \\
\cline { 2 - 9 } & Bylaw & PH & & Bylaw & PH & \\
\cline { 2 - 9 } & Heating & Cooling & Heating & Cooling & Heating & Cooling & Heating & Cooling \\
\hline Historical & 36.1 & 0.5 & 14.1 & 0.4 & 66.5 & 2.1 & 14.9 & 1.8 \\
\hline A2 & 26.5 & 19.8 & 12.6 & 17 & 57.1 & 12.0 & 13.7 & 9.9 \\
Difference & $-27 \%$ & $3860 \%$ & $-11 \%$ & $4150 \%$ & $-14 \%$ & $471 \%$ & $-8 \%$ & $450 \%$ \\
\hline RCP4.5 & 25.7 & 5.1 & 12.6 & 4.3 & 56.8 & 6.0 & 14.0 & 5.0 \\
Difference & $-29 \%$ & $920 \%$ & $-11 \%$ & $975 \%$ & $-15 \%$ & $186 \%$ & $-6 \%$ & $178 \%$ \\
\hline RCP8.5 & 20.4 & 19.5 & 12.1 & 16.9 & 50.9 & 14.6 & 13.5 & 12.0 \\
Difference & $-43 \%$ & $3800 \%$ & $-14 \%$ & $4125 \%$ & $-23 \%$ & $595 \%$ & $-9 \%$ & $567 \%$ \\
\hline
\end{tabular}

\subsection{Overheating risk}

Figure 3 shows that for the base-case the overheating hours represent 55\% (2410 hrs) and $69 \%$ (3018 hrs) of the summer time (April to September) for Fort Nelson and Vancouver, respectively. The overheating hours would be increased by $35 \%$ and $65 \%$ under the 2080 weather data for Vancouver and Fort Nelson, respectively. Improving the energy performance of the base-case to $\mathrm{PH}$ building would increase the overheating hours by $20 \%$ and $10 \%$ under historical weather, while by $57 \%$ and $62 \%$ under 2080 weather for Vancouver and Fort Nelson, respectively. Adding natural ventilation for the base-case can significantly reduce the overheating hours by $86 \%$ and $95 \%$ for Fort Nelson and Vancouver, respectively. However, the natural ventilation measures may not be sufficient under future climate, with 12\% (542 hours) and 18\% (781 hours) of summer time being overheated for Vancouver and Fort Nelson, respectively. The performance of PH building 
with natural ventilation would be slightly better than the base-case with natural ventilation given that the PH building has windows with lower Solar Heat Gain Coefficient. The higher number of overheating hours in Fort Nelson than that in Vancouver when natural ventilation is probably due to the slightly higher solar radiation in Fort Nelson than that in Vancouver, especially in May and June. It could be also attributed to the higher thermal resistance specified for buildings in Fort Nelson.

a)

b)
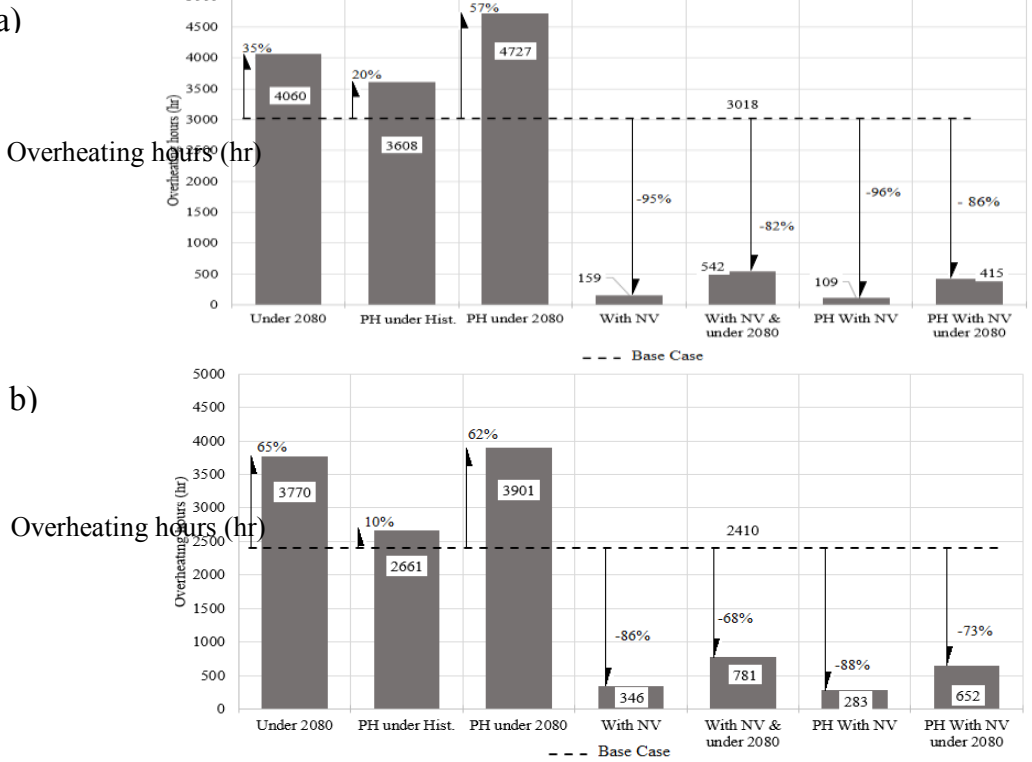

Fig. 3. Number of overheating hours and the percentage difference between base-case and the seven cases investigated for a) Vancouver; and b) Fort Nelson.

\section{Conclusions}

The effect of future climate on the energy performance and thermal comfort of a typical high-rise residential building built in British Columbia, Canada in compliance with bylaw and Passive House standards are studied through simulations. Three emission scenarios, namely, A2 emission scenario, RCP 4.5, and RCP 8.5, are used to generate future weather data. The evaluation is carried out for climate zone 4 and 7 in British Columbia. The results show that:

\section{- Energy performance:}

- For both bylaw and $\mathrm{PH}$ cases, the heating energy demand would be decreased and the cooling energy demand would be significantly increased under future climates for all climate change scenarios.

- With climate change, the cooling energy demand of bylaw building would be increased to account for about $50 \%$ of total energy demand compared to $1 \%$ in the historical year. However, the cooling energy demand of $\mathrm{PH}$ building would become greater than the heating energy demand for Vancouver and failed to meet $\mathrm{PH}$ requirements.

- The total energy consumption would be decreased under the future climates by $5 \%$ for Vancouver, while the energy saving would be greater for the colder climate zone 7, by $30 \%$ for Fort Nelson, under bylaw codes. However, for the PH case, the annual energy consumption would be increased for climate zone 4 by $16 \%$ and $2 \%$ for zone 7 . 


\section{- Overheating risks}

- The climate change would increase the overheating risk, for both bylaw and PH cases by $65 \%$ compared with historical weather without any mechanical cooling, or natural ventilation.

- The natural ventilation measure would significantly reduce the overheating hours, but may not be sufficient, especially for PH building where the overheating still represented $15 \%$ of the summer time.

In conclusion, buildings designed based on historical weather data would perform differently under the changing future climates, and therefore more efforts should be placed on designing buildings that could adapt to climate change. Given that the cooling energy demand would be significantly increased under future years, strategies to provide proper solar control and mitigate overheating risks during summertime would become important design considerations even for cold climates.

We gratefully acknowledge the financial supports received from BC Housing as part of the Building Excellence Research \& Education Grants Program, NSERC Discovery Grant, and Gina Cody School of Engineering and Computer Science, Concordia University.

\section{Reference}

[1] IPCC. Climate Change 2014: Synthesis Report. Contribution of Working Groups I, II and III to the Fifth Assessment Report of the Intergovernmental Panel on Climate Change. Geneva, Switzerland: IPCC. (2014)

[2] Natural Resources Canada. Energy Efficiency Trends in Canada 1990 to 2013. (2016)

[4] NASA global climate change. https:/climate.nasa.gov/vital-signs/global-temperature/

[5] L. Wang, X. Liu, H. Brown. Prediction of the impacts of climate change on energy consumption for a medium-size office building with two climate models. Energy and Buildings. 157. 218-226 (2017)

[6] X. Song, C. Ye. Climate Change Adaptation Pathways for Residential Buildings in Southern China. Energy Procedia. 105. 3062-3067 (2017)

[7] P. Shen. Impacts of climate change on U.S. building energy use by using downscaled hourly future weather data, Energy and buildings. 134. 61-70 (2017)

[8] A. Robert, M. Kummert. Designing net-zero energy buildings for the future climate, not for the past. Building and Environment. 55. 150-158 (2012)

[9] A. Beizaee, K.J. Lomas, S.K. Firth. National survey of summertime temperature and overheating risk in English homes. Building and Environment. 65. 1-17 (2013)

[10] M. Baborska-Marozny, F. Stevenson, M. Grudzinska. Overheating in retrofitted flats: occupant practices, learning and interventions. Building and Research and Information. 45. 40-59 (2017)

[11] A. Pathan, A. Mavrogianni, A. Summerfield, T. Oreszczyn, M. Davies. Monitoring summer indoor overheating in the London housing stock. Energy and Buildings. 141. 361378 (2017)

[12] BC Hydro Power Smart. Building Envelope Thermal Bridging Guide: analysis, application and insights. (2014)

[13] ANSI/ASHRAE Standard-55. Thermal Environmental Conditions for Human Occupancy. (2017)

[14] Canadian Commission on Building and Fire Codes and National Research Council of Canada. National Energy Code of Canada for Buildings. (2017) 